\title{
Formação do enfermeiro-líder a partir da pedagogia de schoenstatt: Desafios e perspectivas
}

\author{
Training of nursing leader from schoenstatt pedagogy: Challenges and perspectives \\ Formación del enfermero-líder de la pedagogía de schoenstatt: Retos y perspectivas
}

Recebido: 20/05/2021 | Revisado: 27/05/2021 | Aceito: 09/06/2021 | Publicado: 23/06/2021

Flávia da Cruz Atarão

ORCID: https://orcid.org/0000-0003-0422-7838

Universidade Franciscana, Brasil

E-mail: flaviaatarao@gmail.com

Eduardo Marques Machado

ORCID: https://orcid.org/0000-0003-1773-3799 Universidade Franciscana, Brasil

E-mail: eduardomarques051@ gmail.com Juliana Silveira Colomé

ORCID: https://orcid.org/0000-0002-8059-1482 Universidade Franciscana, Brasil E-mail: juliana@ufn.edu.br

Naiana Oliveira Dos Santos

ORCID: https://orcid.org/0000-0002-5439-2607

Universidade Franciscana, Brasil

E-mail: naiana.santos@ufn.edu.br

Liliane Alves Pereira

ORCID: https://orcid.org/0000-0001-6354-7781

Universidade Franciscana, Brasil

E-mail: liliane.pereira@ufn.edu.br

\begin{abstract}
Resumo
Objetivo: analisar a liderança dos acadêmicos de enfermagem com base na pedagogia de Schoenstatt. Método: pesquisa qualitativa, desenvolvida através da pesquisa-ação em instituição de ensino superior do sul do Brasil, com seis acadêmicas do sétimo semestre da graduação em enfermagem, por meio de questionário semiestruturado, analisadas mediante análise textual discursiva. Resultados e discussão: participaram da pesquisa seis acadêmicas todas do sexo feminino com idade entre 23 e 33 anos, todas já tinham entrado em contato com algum material sobre liderança, da qual tinham um conceito previamente elaborado. A partir da análise dos dados surgiram duas categorias descritas a seguir: o amor e a confiança como características essenciais de um líder; o autoconhecimento como ferramenta no processo de desenvolvimento da liderança. Considerações finais: os elementos que compõem a pedagogia de Schoenstatt abordados neste estudo contribuem para a formação acadêmica de enfermeiros-líderes diante das exigências atuais dos serviços de saúde e promove uma formação que sinaliza as perspectivas do ser líder. Palavras-chave: Liderança; Enfermagem; Pesquisa qualitativa.
\end{abstract}

\begin{abstract}
Objective: to analyze the leadership of nursing students based on Schoenstatt's pedagogy. Method: qualitative research, developed through action research in a higher education institution in southern Brazil, with six academics from the seventh semester of undergraduate nursing, through a semi-structured questionnaire, analyzed through discursive textual analysis. Results and discussion: six female academics participated in the research, all female, aged between 23 and 33 years old, all of whom had already come into contact with some material on leadership, from which they had a previously elaborated concept. From the data analysis, two categories emerged, described below: love and trust as essential characteristics of a leader; self-knowledge as a tool in the leadership development process. Final considerations: the elements that make up Schoenstatt's pedagogy addressed in this study contribute to the academic training of nurse leaders in view of the current demands of health services and promote training that signals the perspectives of being a leader.
\end{abstract}

Keywords: Leadership; Nursing; Qualitative research.

\section{Resumen}

Objetivo: analizar el liderazgo de los estudiantes de enfermería basado en la pedagogía de Schoenstatt. Método: investigación cualitativa, desarrollada a través de investigación acción en una institución de educación superior en el sur de Brasil, con seis estudiantes del séptimo semestre de licenciatura en enfermería, a través de un cuestionario semiestructurado, analizado mediante análisis textual discursivo. Resultados y discusión: en la investigación 
participaron seis académicas participantes entre 23 y 33 años, todas ellas ya habían estado en contacto con algún material sobre liderazgo, del cual tenían un concepto previamente elaborado. Del análisis de los datos surgieron dos categorías, que se describen a continuación: el amor y la confianza como características esenciales de un líder; el autoconocimiento como herramienta en el proceso de desarrollo del liderazgo.Consideraciones finales: los elementos que componen la pedagogía de Schoenstatt abordada en este estudio contribuyen a la formación académica de las enfermeras líderes ante los requerimientos actuales de los servicios de salud y promueven una formación que señale las perspectivas de ser líder.

Palabras clave: Liderazgo; Enfermería; Investigación cualitativa.

\section{Introdução}

A liderança torna-se cada vez mais imprescindível na atuação dos profissionais da enfermagem nos diferentes campos de trabalho e consiste na capacidade de influenciar os outros a partir da própria personalidade. Entretanto, para que o líder seja influente ele precisa ser capaz de liderar-se a si mesmo (Maxwell, 2008).

O termo liderança desde o inglês arcaico leadem, até o sentido atual significa conduzir, guiar, orientar, encaminhar. Na sua essência a palavra liderança já carrega as qualidades que o líder deve desenvolver para exercer uma liderança de excelência e qualidade, ser capaz de estar com o outro e motivá-lo na busca do objetivo comum (Bergamini,1994).

A liderança necessita ser incentivada por habilidades inovadoras, união de uma equipe e competência técnica e cientifica. $\mathrm{O}$ ato de liderar, tem como propósito a busca de melhores resultados, se relacionar com as problemáticas e superalas. O enfermeiro líder, atua junto com sua equipe de trabalho, identifica potencialidades e fragilidades, assume a confiança da mesma e assume mudanças por melhores resultados (Silva et al., 2017).

A capacidade de um enfermeiro liderar está ligada a capacidade do mesmo se comunicar, em trabalho em equipe e seguro. Onde as relações interpessoais são um imperativo para a construção do enfermeiro líder, sendo estimulada e desenvolvida em todos os contextos (Roque et al., 2020).

Assumir o papel de liderar é uma das principais funções do profissional enfermeiro, que está relacionada na capacidade de tomada de decisões. O conhecimento teórico-prático, junto a proatividade para formar enfermeiros lideres desde o processo formativo, até o momento de se tornar responsável pela tomada de decisão (Costa et al., 2017).

Diante do grande desafio de suscitar bons líderes na enfermagem para o mercado de trabalho, Schoenstatt com seus recursos científicos, éticos e espirituais apresenta ferramentas que atuam diretamente na personalidade de cada indivíduo, tornando-o protagonista de seu próprio desenvolvimento (Siegel, 2004).

O sistema pedagógico de Schoenstatt se baseia na prática pedagógica e na concepção de educação do Pe.Kentenich. Para ele, educar consiste basicamente em gerar vida e servir à vida. Schoenstatt como movimento, quer ser um "oficial de enlace entre a teoria e a prática". Com isso ele indica: o que lhe interessa não é, em primeiro lugar, a proclamação da doutrina em si mesma, mas que está se encarne e se torne vida.

Esta afirmação se confirma através de conceitos como autoeducação e autoconhecimento, conceitos básicos do vocabulário schoenstatiano, tornando-o um instrumento inovador e eficaz na formação em liderança, também na enfermagem.

Neste sentido, a pedagogia de Schoenstatt com suas cinco "estrelas condutoras": pedagogia do ideal, pedagogia da vinculação, pedagogia da aliança, pedagogia da confiança e pedagogia do movimento (das correntes de vida), é uma pedagogia que valoriza e instiga a liderança tornando-se uma importante ferramenta no processo de formação do profissional de enfermagem como enfermeiro-líder.

$\mathrm{Na}$ presente pesquisa foram abordadas duas das cinco "estrelas condutoras" que sustentam está pedagogia: A pedagogia do ideal e a pedagogia das vinculações. Isto porque elas contemplam plenamente o exercício da liderança em enfermagem, abordando elementos essenciais no processo de cuidado em saúde e a busca cotidiana do enfermeiro em exercer com eficácia e eficiência seu exercício profissional. 
A pedagogia do ideal trabalha a partir do autoconhecimento visa potencializar as características éticas intrínsecas e originais de cada indivíduo partindo de uma visão pessoal de si mesmo, chamada de ideal pessoal, onde o mesmo através de uma séria e contínua autoeducação aperfeiçoa as características de sua personalidade em prol da conquista dos objetivos da instituição onde ele está inserido; é uma formação do ideal para o ideal, (Kastner, 2012).

A pedagogia das vinculações fundamenta-se em duas virtudes, o amor e a confiança, que no processo de humanização dos serviços que envolvem o cuidado com o ser humano, são características indispensáveis para uma liderança qualificada que ajuda os seus liderados a buscarem o que melhor tem de si e empenharem pela instituição que estão servindo (Schlickmann, 2012; Martins, et al, 2012).

Dessa forma, o presente estudo se justifica em virtude da constatação que, apesar de imprescindível na atuação do enfermeiro, a liderança ainda é um tema pouco desenvolvido na formação e na atuação do mesmo nos campos de trabalho. Tal constatação decorre da condição de muitos profissionais da enfermagem ainda negarem como sua a competência referente às questões gerenciais, administrativas e de liderança dentro das equipes como reflexo de uma lacuna que começa na formação profissional no ensino superior. A pedagogia de Schoenstatt pode ser considerada uma ferramenta adequada para trabalhar a personalidade enriquecendo-a de valores éticos, morais e espirituais para que a liderança realmente ocupe o lugar que lhe corresponde na enfermagem.

Diante do exposto e buscando potencializar a capacidade de liderança dos acadêmicos de enfermagem propôs-se como questão de pesquisa: como a pedagogia de Schoenstatt pode incentivar a formação do enfermeiro-líder? Para responder à questão pesquisa objetivou-se: analisar a liderança dos acadêmicos de enfermagem com base na pedagogia de Schoenstatt; discutir a pedagogia de Schoenstatt como instrumento de formação para a liderança em enfermagem; analisar a compreensão dos acadêmicos sobre liderança schoenstatiana.

\section{Metodologia}

Trata-se de uma pesquisa, com abordagem qualitativa desenvolvida através da pesquisa-ação. Este processo metodológico é empírico interpretativo e une simultaneamente pesquisa e ação. Compõe de quatro a oito etapas. Contudo, a proposta selecionada para este estudo foi de quatro etapas, conforme figura abaixo, por estas darem conta do objetivo do estudo e pela pesquisadora estar imersa no cenário pesquisado (Thiollent, 1997).

Figura 1. Fluxograma referente ao percurso metodológico.

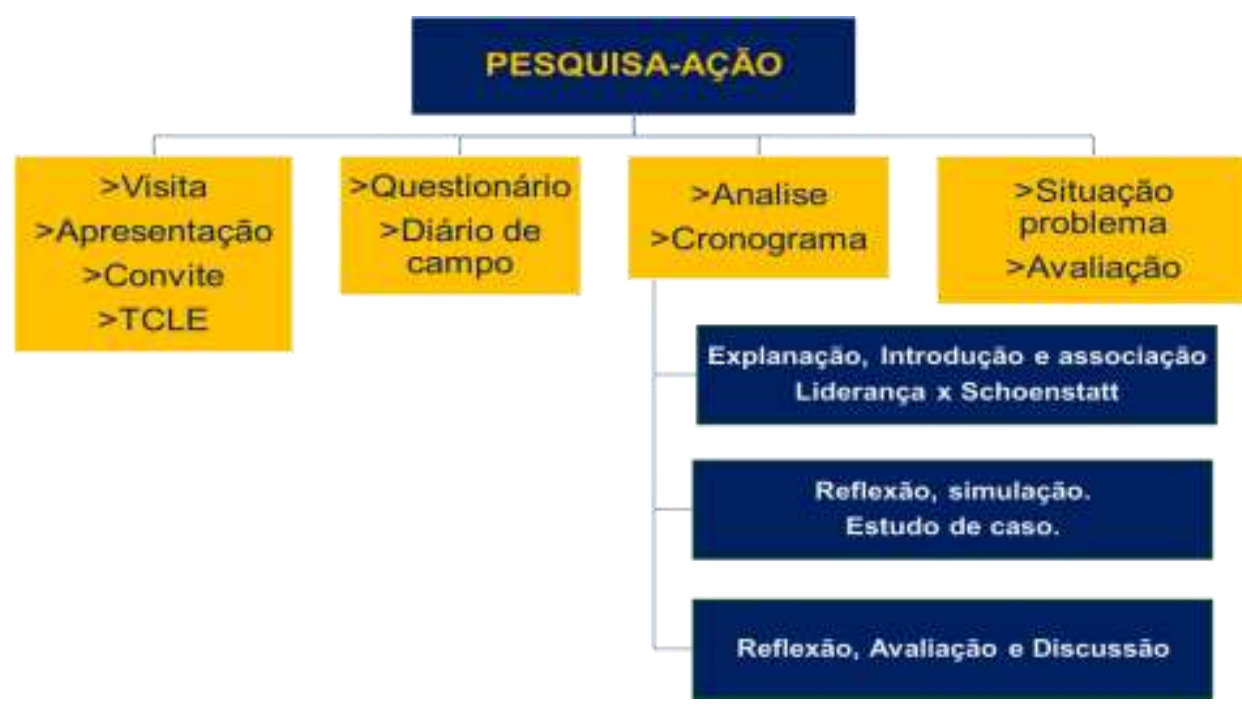

Fonte: Autores. 
O estudo foi desenvolvido com acadêmicos do curso de enfermagem, de uma universidade privada, situada na região central do Rio Grande do Sul. Os critérios de inclusão foram: cursar enfermagem na referida universidade, estar cursando o sétimo semestre e participar integralmente das atividades propostas. Os critérios de exclusão foram: não participar dos encontros propostos, em virtude de licença saúde ou atividade de regime domiciliar, ter cursado a disciplina de Organização e gestão na saúde e enfermagem em outra instituição de ensino superior e não responder as perguntas do questionário; considerando os critérios apresentados 18 acadêmicos foram os convidados a participar da pesquisa, destes 10 responderam o questionário. Sendo que seis acadêmicas corresponderam aos critérios de inclusão mencionados.

Os dados foram coletados na Instituição, em local e horário previamente agendados com os participantes do estudo. O período da coleta de dados compreendeu os meses de agosto e setembro do ano de 2018.

A técnica de coleta de dados considerou quatro etapas, descritas a seguir, sendo que cada etapa tinha a duração em média de duas horas: etapa 1- Foi realizada uma visita aos acadêmicos, apresentado o objetivo da pesquisa, convidando-os a participarem da mesma. Após os acadêmicos aceitarem o convite foi entregue o Termo de Consentimento Livre e Esclarecido (TCLE) e o Termo de Confidencialidade. A etapa 2- compreendeu a aplicação de um questionário semi-estruturado com questões que abordavam o conceito de liderança, as potencialidades e fragilidades das acadêmicas no exercício da liderança e o autoconhecimento como espaço de liderança. Sendo que, estas questões foram respondidas mediante conhecimento prévio que os acadêmicos já possuíam seja em virtude da formação acadêmica, seja na formação pessoal/ social. Foi possível explorar também o diário de campo como parte da observação não participante, uma vez que, a observação e as anotações ajudaram na formulação do material que compôs a etapa 3.

Etapa 3- foram analisadas as respostas provenientes do questionário e a partir destas foi desenvolvido um cronograma de encontros, totalizando três encontros: No primeiro foi feito uma explanação geral de conceitos de liderança, uma introdução na pedagogia de Schoenstatt e de sua relação com a liderança enfocando principalmente a pedagogia das vinculações e a pedagogia do ideal. No segundo encontro foi apresentado ao grupo uma mensagem reflexiva, onde cada uma partilhou as suas impressões e depois foi lançado um estudo de caso como disparador e solicitado às participantes para que se manifestassem em relação ao caso como líderes. No terceiro encontro foi proposto às participantes um momento de reflexão onde cada uma fez sua avaliação pessoal a respeito dos encontros e após foram mostrados alguns vídeos sobre liderança e feito uma roda de discussão a partir de alguns disparadores que incitavam a liderança. A duração média desses encontros foi de duas horas.

$\mathrm{Na}$ etapa 4- foi aplicada uma situação problema como metodologia ativa para identificar a apreensão das acadêmicas no que se refere a temática após os encontros, atividades, intervenções e o impacto destes na formação dos enfermeiros como líderes, sendo possível identificar tanto a apreensão como o envolvimento das acadêmicas na proposta. Esta etapa compreendeu a avaliação, pois fora capaz de mensurar as transformações ocorridas ao longo dos encontros.

Os dados foram analisados a partir da Análise Textual Discursiva, que compreende uma metodologia de análise de dados qualitativos que tem por finalidade produzir novas compreensões sobre discursos e fenômenos (Moraes, Galiazzi, 2013). Essa análise caracteriza-se como um processo auto organizado de construção e de compreensão, onde novos entendimentos surgem através de uma sequência de quatro etapas: a desmontagem dos textos ou unitarização; o estabelecimento de relações ou categorização; a captação do novo emergente e a construção de um processo auto organizado (Moraes, Galiazzi, 2013).

$\mathrm{Na}$ etapa da unitarização foram examinados detalhadamente os questionários fragmentando-os até atingir unidades de sentido, as quais constituem-se de enunciados referentes ao fenômeno pesquisado (Moraes, Galiazzi, 2013). Na categorização foram estabelecidas relações entre as unidades de sentido, agrupando-as na formação de conjuntos a partir da articulação de significados semelhantes e constitui-se a categorização das unidades anteriormente obtidas, sendo a priori ou emergentes (Moraes, Galiazzi, 2013). Na comunicação foi realizado a construção de um processo auto organizado em que tem sua origem na primeira fase da análise com o movimento de desconstrução do corpus e seguindo ao final do processo analítico com a 
emergência de novas compreensões que foram comunicadas e validadas sob a forma escrita (Moraes, Galiazzi, 2011).

$\mathrm{Na}$ última etapa a captação do novo emergente consistiu na emergente compreensão do que se caracterizou pela obtenção do metatexto, que permitiu criar, a partir de vozes emergentes nos textos analisados, o que as participantes aprenderam do conceito de liderança a partir da pedagogia de Schoenstatt, sendo explanados em três categorias. Nessa etapa percebeu-se o surgimento de novos conceitos ou definições de liderança a partir de cada corpus construído anteriormente, e definidos a partir de saberes significantes (Moraes, Galiazzi, 2011).

Os aspectos éticos foram respeitados, conforme as recomendações da Resolução 466/2012 do Conselho Nacional de Saúde (Brasil, 2012), no que se refere aos aspectos éticos das pesquisas envolvendo seres humanos. O artigo faz parte do trabalho final de graduação como fruto da aplicação de um projeto previamente apresentado a coordenadora do Curso de enfermagem da Instituição (conforme protocolo) e após a aceitação do mesmo o projeto foi encaminhado ao Comitê de Ética e Pesquisa (CEP) da Universidade Franciscana tendo sido aprovado sob o número 2.793.110.

\section{Resultados e Discussão}

Participaram da pesquisa seis acadêmicas todas do sexo feminino com idade entre 23 e 33 anos, todas já tinham entrado em contato com algum material sobre liderança, da qual tinham um conceito previamente elaborado. Entretanto, ao associá-lo com a pedagogia de Schoenstatt as participantes não conseguiram conceituar o termo e correlacioná-lo.

A partir da análise dos dados surgiram duas categorias descritas a seguir: o amor e a confiança como características essenciais de um líder; o autoconhecimento como ferramenta no processo de desenvolvimento da liderança.

As acadêmicas para terem sua identidade preservada serão identificadas conforme as duas falas pelo código "AC" seguido dos algoritmos que variam do um ao seis. Por exemplo, "AC 1".

\subsection{O amor e a confiança como características essenciais de um líder}

Nesta categoria foi possível evidenciar os componentes referentes à liderança no contexto da pedagogia de Schoenstatt, identificados pelas acadêmicas a partir do domínio qualidades pessoais, relacionados ao domínio das características que fazem parte do exercício da liderança, sendo que todas as características elencadas nas qualidades pessoais e nas características são um desdobramento do amor e da confiança e ajudam no exercício da liderança nas relações interpessoais.

Um líder necessita compreender suas próprias emoções. Pode se definir a inteligência emocional como o equilíbrio entre emocional e racional, o líder carece de amor e confiança para determinar seu comportamento e seu raciocínio (Pôrto; Tartarotti; Bagattini, 2020).

No que se refere ao amor e a confiança as acadêmicas relataram que o líder só pode desempenhar a sua capacidade de influenciar pessoas e conquistar seguidores se em suas relações interpessoais esses sentimentos ou atitudes estiverem presentes. Foi evidenciado recorrentemente a importância do amor como impulso para a conquista da liderança e principalmente como característica essencial do enfermeiro e que através dele se desdobra a confiança da equipe e dos pacientes.

“A confiança com amor e sabedoria, que é o que os pacientes muitas vezes buscam em nós (enfermeiros) ..." ou ainda "Com a confiança através do amor conquistar estes seguidores..." (AC 03)

"Penso que o amor é a palavra que move tudo, que move um líder..." E "Um líder deve amar, influenciar positivamente..." (AC 06)

A pedagogia das vinculações baseia-se em duas virtudes: o amor e a confiança, características indispensáveis para o líder. A confiança é a base de todas as relações, e o amor deve ser colocado antes da técnica e a serviço dos colaboradores, eles 
devem sentir-se amados pelo seu líder e assim automaticamente confiarão nele (Schlickmann, 2012; Martins, et al, 2012). Principalmente quando o exercício da liderança tem como objetivo primordial o cuidado clínico, responsável e ético para com o outro.

"É preciso termos confiança em nós mesmo para nos sentirmos seguro...” "Entendi a importância da confiança, que é preciso conhecermos nossa equipe e confiarmos neles." (AC 02)

"Hoje posso compreender mais sobre o amor, sobre a importância de amar o que faço e fazer por amor, amar a mim e os meus semelhantes. Algo que ficou muito marcado para mim foi quando foi nos falado que é possível amar as pessoas sem lidera-las, mas não é possível liderar sem amá-las." (AC 01)

Para o conceito de liderança servidora o amor torna-se uma marca, não que o líder tenha seu papel confundido com sua equipe de trabalho, antes porque ele se considera parte da equipe, confia em si, tem capacidade de confiar e se importar com o outro e ao mesmo tempo assume como um influenciador em busca do objetivo comum.

A liderança servidora consiste na capacidade de influência que o líder serviçal passa a exercer na equipe a partir de uma verdadeira conquista de cada membro regida pelos comportamentos do compromisso, escuta, respeito e amor. É apontada como uma das mais promissoras estratégias de comportamento relacional entre líder e equipe, principalmente na enfermagem, pois responde ao perfil que toda equipe anseia contemplar em seu líder, ela une num único estilo o potencial visionário e a implementação através da ação (Blanchard, 2007, Nunez; Muniz, 2016).

A confiança e o amor tornam-se então caminhos essenciais para o exercício da liderança fundamentados na consciência de si e da função que o líder deve exercer, uma vez que, a ele e a toda equipe é confiado um objetivo comum alcançado em virtude de um fazer conjunto e uníssono.

"Acredito que autoconhecimento e o amor são essenciais para uma efetiva liderança, e que o "sucesso" se encontra muito mais na simplicidade, humildade e amor que em outras coisas." (AC 04)

$\mathrm{O}$ amor como necessidade humana intrínseca à pessoa humana, funda-se no respeito pela singularidade do outro. Cabe ao líder amar a cada um de sua equipe com amor serviçal, ou seja, com um amor desprendido que sempre procura dar o exemplo pelo servir generoso e desprendido, não como meio para satisfazer as suas necessidades pessoais, mas para despertar em cada um de seus liderados o potencial que carregam consigo, amor neste sentido se expressa como o cuidado e a preocupação pelo bem-estar do outro.

Diante de todas as habilidades que o enfermeiro-líder precisa desenvolver destacam-se: capacidade de criar vínculos, comunicação, confiança, criatividade, amor, interpersonalidade, serviçalidade, humildade, verdade. E o primeiro passo para que ele alcance esses pré-requisitos está relacionado com o seu próprio autoconhecimento. O líder só é capaz de liderar os outros quando é capaz de liderar-se a si mesmo (Nunez; Muniz, 2016).

\subsection{O autoconhecimento como ferramenta no processo de desenvolvimento da liderança}

Nesta categoria foi possível evidenciar através das colocações escritas e verbais, sendo as escritas foram feitas pelas acadêmicas em papel previamente selecionado e as verbais, anotadas pela pesquisadora durante os encontros. Evidenciou que o autoconhecimento é uma das características específicas da liderança e que através deste mecanismo se aperfeiçoa e desenvolve essa habilidade em cada pessoa. Nos domínios referentes às características que um líder possui destacou-se autoconhecimento, conhecimento, humildade, reconhecimento e sabedoria.

A liderança surge no ato de liderar a si mesmo, para isso é necessário o autoconhecimento, auxiliando o autodesenvolvimento, como reformular atitudes e perceber melhor os próprios pontos positivos e negativos. Com o autoconhecimento se torna possível traçar o caminho, inspirar uma visão compartilhada, desafiar o processo, capacitar os outros a agir e encorajar o ânimo (Biegelmeyer et al., 2020). 
$\mathrm{O}$ autoconhecimento surge nas falas das acadêmicas como um processo constante e que ajuda a entender melhor os outros e a fazer menos (pre) julgamentos, ainda foi definido como um processo de construção do próprio eu e que muito mais do que avanços exteriores precisa-se buscar sempre mais aprofundar e desvendar o interior para assim exercer uma liderança coerente.

Neste processo de autoconhecimento a pedagogia de Schoenstatt, é uma ferramenta de altíssima abrangência e eficácia para a formação do enfermeiro-líder capaz de liderar-se a si mesmo e a sua equipe.

"Conhecer a si mesmo para com exemplos influenciar seguidores. No processo todo o que ficou evidenciado para mim foi a questão de conhecer-se, da importância de trabalhar o próprio "eu" e ser espirituoso para então conquistar autoridade e ter seguidores. A ciência e os avanços são muito importantes, mas antes disso, de dominar toda a tecnologia devemos dominar o conhecimento do nosso interior." (AC 01)

Pelo autoconhecimento o enfermeiro-líder tem condições de reconhecer as suas potencialidades e fragilidades, saber administrá-las de forma que não prejudiquem o desempenho da equipe, coloca sua experiência a serviço e diante das exigências e imparcialidades as quais o serviço está sujeito manifesta-se como um colaborador do bem comum.

O autoconhecimento é tão importante que pode ser considerado uma prova de amor do líder para sua equipe. Atualmente é inconcebível um líder que não tenha visitado a escola do autoconhecimento, pois aquele que quer liderar primeiro deve ter condições de ser líder de si mesmo e isso só é possível a partir do autoconhecimento (Grün, 2006).

"Pois acredito que o autoconhecimento e o amor são essenciais para uma efetiva liderança." (AC 04).

"É preciso ser motivado para que se possa motivar os demais, entendendo que os erros e tropeços durante a caminhada torna a pessoa mais humilde... Tornando-a um ser humano melhor." (AC 05)

A liderança não pode ser confundida com relações de cumplicidade ou submissão do liderado. A relação de afeto que perpassa a liderança são a busca do objetivo comum, a essencialidade e a aceitação da autonomia de cada pessoa envolvida no cenário, bem como, o reconhecimento de que cada pessoa está comprometida com o objetivo comum e com seu próprio crescimento.

Portanto, a capacidade de influenciar as pessoas para uma finalidade de bem comum para o grupo que se está inserido, perpassa diferentes realidades, e considera para tanto, o meio, os sujeitos, o ambiente, o trabalho, a equipe e o objeto em questão (Akerjordet, Severinsson, 2010).

Apesar de salutar é sabido que o autoconhecimento além de ensinar a alegrar-se com a condição de pessoa humana, com o ser e sua originalidade, é uma atividade que exige muita perseverança e determinação pois, é difícil superar a realidade de erros e limites da própria personalidade e inúmeros são os obstáculos que se apresentam quando se decide por um conhecimento de si mesmo, visto que hodiernamente trabalha- se para tornar as pessoas cada vez mais massificadas e menos conhecedoras das riquezas que carregam em si (Schlickmann, 2018). Autoconhecer-se é considerado semelhante a uma "prova de fogo", quem nunca foi provado pelo fogo, não sabe quem é. E, se não sabe quem é, não pode ser um líder (Jones, 2006).

A capacidade de se vislumbrar como um líder que tem seu ideal voltado para o desenvolvimento de si, para o reconhecimento de suas fragilidades e potencialidades o torna apto a trilhar com maestria o caminho do autoconhecimento e se coloca como um modelo para toda a equipe, consciente de quem se é e de quem deseja ser.

"Diversas vezes nas falas, ficou claro quanto a importância de nos conhecermos." (AC 02)

"Que sejamos um exemplo e que nossa equipe nos veja e queira ser um espelho do nosso caráter." (AC 02)

O conhecimento pessoal leva o exercício da liderança para um espaço dialógico, entendido a partir das motivações e percepções das pessoas envolvidas no processo, e isso torna o exercício da liderança mais sólido e (com) partilhado.

O fundador da pedagogia de Schoenstatt, padre José Kentenich define o ser humano como um microcosmos, um pequeno mundo que precisa ser descoberto e aprofundado diante das grandes mudanças e avanços pelos quais passa a 
sociedade, quanto mais se avança exteriormente em tecnologia e conhecimento científico maior deve ser o autoconhecimento e o avanço interior (Schlickmann, 2012).

Dentro da pedagogia de Schoenstatt, o aprofundamento do eu através do autoconhecimento e da autoeducação é o eixo central na formação de personalidades capazes de assumirem grandes tarefas nas diferentes profissões onde atuam, sendo líderes que exercem influência sobre seus liderados sem se tornarem chefes opressores (Schlickmann, 2018).

Neste processo de busca interior surge o que a seguir será abordado que é o ideal, neste caso o ideal pessoal que como fruto do autoconhecimento manifesta o cerne da personalidade e move a pessoa a uma constante busca através de exercícios de autoeducação (Siegel, 2004).

\section{Conclusão}

Nesta pesquisa foi possível perceber que as questões ligadas à personalidade, são determinantes na atuação dos futuros profissionais que estão em formação acadêmica e como cada vez mais as atitudes destes são determinadas pelo movimento interior de suas emoções, vivências, crenças e conhecimentos. Na medida que cada um se permite desvendar os recônditos de seu interior mais se encontra com o cerne de sua personalidade e consegue olhar nos olhos daquilo que realmente é. Nota-se ainda que apesar de ser difícil este processo de autoconhecimento, é uma demanda crescente nas pessoas, pois muitos problemas acontecem em decorrência da falta de autoconhecimento.

Outro fator interessante é o crescente movimento e os laços vinculares que possuem as duas categorias apresentadas a primeira é voltada para a realidade pessoal do líder como características próprias, pois o amor e a confiança são características essenciais de um líder; a segunda é um instrumento capaz de ajudar o líder no exercício da liderança, sendo que, o autoconhecimento como ferramenta no processo de desenvolvimento da liderança.

Destaca-se o conceito de personalidade, como o ideal ético, enriquecido com as características inconfundíveis, singulares e individuais de cada pessoa, ou seja, são as particularidades que cada um carrega consigo e que formam o "cerne da personalidade". Esse é o fator fundamental para se alcançar a verdadeira liderança schoenstatteana, só personalidades autênticas conseguirão cultivar um alto nível de valores éticos fundamentais para liderar.

O estudo busca contribuir para a formação de enfermeiros líderes, na exposição das teorias, como a pedagogia de Schoenstatt, em seu processo de formação acadêmica e que cada vez mais é preciso oportunizar experiências de encontro consigo mesmo, como ferramenta para lapidar personalidades enriquecidas de valores éticos, morais, científicos e espirituais que na sociedade tornam-se agentes transformadores do meio onde atuam. A limitação deste estudo se deva ao fato de que sua realização com uma amostra específica de acadêmicos de enfermagem em uma Instituição de Ensino Superior do sul do Brasil, fato que não permite a generalização dos resultados. Entretanto, é possível seguir pesquisando esta pedagogia como forma de fortalecimento do ser e fazer do enfermeiro no exercício da liderança, corroborando ainda com a solidificação da profissão nos diferentes espaços de gestão.

Diante do exposto, se faz necessário estudos com maior amostragem, acerca da pedagogia de schoenstatt frente ao exercício da liderança. Assim, trazendo resultados mais comparáveis com estudantes de enfermagem e/ou enfermeiros a nível nacional, visto a presença dos mesmos em todo o território brasileiro.

\section{Referências}

Akerjordet, K. \& Severinsson, E. (2010). The state of the science of emotional intelligence related to nursing leadership: an integrative review. Journal of Nursing Management. 18: 363-382. https://doi.org/10.1111/j.1365-2834.2010.01087.x

Bergamini, C. W. (1994). Liderança: administração do sentido. São Paulo: Atlas. 
Biegelmeyer, U. H., Vacarig., Bernardif. C., Camargom. E. \& Cracot, T. (2020). Criação de conhecimento na liderança e desenvolvimento de novos líderes. P2P E Inovação, 7 (1): 205-226. https://doi.org/10.21721/p2p.2020v7n1.p205-226

Blanchard, K. (2007). Liderança de alto nível. Porto Alegre: Bookman.

Brasil. Ministério da Saúde. Conselho Nacional de Saúde. (2012). Resolução no 466, de 12 de dezembro de 2012. Aprova as diretrizes e normas regulamentadoras de pesquisa envolvendo seres humanos. Brasília. https://bvsms.saude.gov.br/bvs/saudelegis/cns/2013/res0466_12_12_2012.html

Costa, S. D., Silva, P. L. N., Gonçalves, R. P. F., Soares, L. M., Filho, W. A. \& Souto, S. G. T. (2017). O exercício da liderança e seus desafios na prática do enfermeiro. J Manag Prim Heal Care., 8 (1):49-65. https://doi.org/10.14295/jmphc.v8i1.257

Grün, A. (2006). A sabedoria dos monges na arte de liderar pessoas. Petropólis, Rio de Janeiro: Vozes.

Kastner, P. F. (2012). Sob a proteção de Maria. Santa Maria: Sociedade Mãe Rainha.

Martins, E. C. B., Silva, I. M. B. P., Bustos, L. C. S. \& Rosa, A. T. R. O. (2012). Liderança servidora: o modelo Southwest Airlines. Revista de Ciências Gerenciais,16 (24):189-202. https://doi.org/10.17921/1415-6571.2012v16n24p\%25p

Martins, E. C. B. et al. (2008). Você nasceu para liderar. Rio de Janeiro: Thomas Nelson Brasil.

Maxwell, J. C. (2007). As 21 irrefutáveis leis da liderança. Rio de Janeiro: Thomas Nelson Brasil.

Moraes, R. \& Galiazzi, M. C. (2013). Análise Textual Discursiva. 3. ed. rev. Ijuí: Ed. Unijuí.

Moraes, R. \& Galiazzi, M. C. (2011). Análise Textual Discursiva. 2. ed. rev. Ijuí: Ed. Unijuí.

Nunes, E. C. D. A. \& Muniz, E. L. (2016). A enfermagem diante do espelho desvelando a liderança transpessoal no cuidado da equipe. Rev Gaúcha Enferm. 37 (4): e63815. http://dx.doi.org/10.1590/1983-1447.2016.04.63815

Pereira, L. A., Hirsch, C. D., Silveira, R. S., Barlem, J. G. T., Schalenberger, C. D. \& Barlem, E. L. D. (2018). Nurse-leader construction process barriers: an ethnonursing. Journal of Nursing UFPE on line, 12 (5):1381-1389. https://doi.org/10.5205/1981-8963-v12i5a234546p1372-1380-2018

Pôrto, M. G., Tartarotti, L. \& Bagattini, L. C. (2020). Inteligência Emocional e o Perfil dos Líderes de uma Cidade na Serra Gaúcha. Saber Humano, 10 (16): 96-114. https://doi.org/10.18815/sh.2020v10n16.423

Roque, T. da S., Silva, B. T. da., Rosa, B. M. da., Santos, C. de S. C. S., Garcia, E. de Q. M. \& Sousa, J. I. dos S. (2020). Liderança da enfermagem em cuidados paliativos. Pesquisa, Sociedade e Desenvolvimento, [S. 1.], v. 9, n. 5, pág. e99953249, 2020. DOI: https://doi.org/10.33448/rsd-v9i5.3249

Schlickmann, D. M. (2018). Anos decisivos: Padre José Kentenich da Ordenação Sacerdotal à Fundação de Schoenstatt. Santa Maria: Sociedade Mãe Rainha.

Schlickmann, D. M. (2012). Tempestades de outono: 1912 o início de uma revolução interior. Santa Maria: Sociedade Mãe Rainha.

Siegel, W. P. (2004). Un educador profetico: fundamentos sicológicos de la pedagogía del Padre Kentenich. Chile: Editorial Patris.

Silva, V. L. S., Camelo, S. H. H., Soares, M. I., Resck, Z. M. R., Chaves, L. D. P., Santos, F. C. \& Leal, L. A. (2017). Práticas de liderança em enfermagem hospitalar: uma self de enfermeiros gestores. Rev. esc. enferm. USP, 51:e03206. http://dx.doi.org/10.1590/S1980-220X2016024403206

Thiollent, M. (1997). Metodologia da pesquisa-ação. São Paulo: Cortez \& Autores Associados. 